\title{
TRATAMENTO TÉRMICO DA BENTONITA NÃO INTERFERE NA CAPACIDADE DE ADSORÇÃO DA AFLATOXINA B
}

\section{J. NONES ${ }^{1}$, J. NONES ${ }^{2}$, R.A. ANTUNES BOCA SANTA ${ }^{1}$, H.G. RIELLA ${ }^{1}$ e N. C. KUHNEN $^{1}$}

\author{
${ }^{1}$ Universidade Federal de Santa Catarina, Departamento de Engenharia Química e Engenharia \\ de Alimentos \\ ${ }^{2}$ Universidade Federal de Santa Catarina, Departamento de Biologia Celular Embriologia e \\ Genética \\ E-mail para contato: janaina.nones@posgrad.ufsc.br
}

\begin{abstract}
RESUMO - Tratamentos físico-químicos podem afetar as características estruturais das bentonitas, alterando sua capacidade de adsorção. O objetivo deste trabalho foi comparar a capacidade da bentonita in natura e tratada termicamente em adsorver a aflatoxina $\mathrm{B}_{1}\left(\mathrm{AFB}_{1}\right)$. Para tal, amostras de bentonita provenientes de Santa Catarina foram calcinadas a temperatura de $500{ }^{\circ} \mathrm{C}$. A caracterização deste material foi realizada através das técnicas de espectroscopia no infravermelho e por dispersão de energia. Os ensaios de adsorção foram realizados em espectrofotometria de UV/vis. Os resultados demonstraram que a bentonita tratada termicamente apresentou uma redução nas bandas em torno da região de $3500 \mathrm{~cm}^{-1}$, além de variações nos percentuais de oxigênio, carbono e ferro. No entanto, não foram observadas diferenças na adsorção. Considerando estes fatores, novos estudos precisarão ser realizados para que materiais mais eficazes para o controle das micotoxinas possam ser desenvolvidos.
\end{abstract}

\section{INTRODUÇÃO}

Bentonita é uma argila constituída principalmente pela montmorilonita, um argilomineral do grupo da esmectita. (Bhuiyan et al., 2013). A montmorilonita é constituída por uma camada de argilomineral 2:1, formada por uma folha octaédrica contendo íons $\mathrm{Al}^{3+} \mathrm{e}$ $\mathrm{Mg}^{2+}$, entre duas folhas de tetraedros de silício (Alver e Alver, 2012). Esta estrutura e composição química são responsáveis por várias propriedades das bentonitas, incluindo área de superfície específica elevada, capacidade de troca catiônica e propriedades de adsorção (Cótica et al., 2011).

Devido à capacidade de adsorção das bentonitas, estas são normalmente utilizadas como adsorventes de micotoxinas, dentre elas, das aflatoxinas (Magnoli et al., 2008). As aflatoxinas são substâncias tóxicas produzidas por fungos filamentosos e estão presentes em uma grande variedade de grãos e oleaginosas (Giordano et al., 2012; Nones et al., 2012). Dentre as aflatoxinas, a aflatoxina $\mathrm{B}_{1}\left(\mathrm{AFB}_{1}\right)$ é considerada potencialmente mais tóxica, sendo classificada como um composto altamente carcinogênico, teratogênico e mutagênico 
(Shim et al., 2014). Além disso, $\mathrm{AFB}_{1}$ é capaz de suprimir o sistema imunológico e induzir citotoxicidade (Hamidi et al., 2013; Nones et al., 2013). Quando presente nos alimentos e consumida em doses elevadas, as aflatoxinas são capazes de ocasionar severas intoxicações, podendo levar os pacientes ao óbito (Mallmann et al., 2011).

Considerando os problemas que esses contaminantes alimentares ocasionam a saúde e à produção animal, medidas capazes de minimizar riscos de intoxicação são de extrema relevância. O uso de bentonitas naturais e tratadas física e/ou quimicamente, com o intuito de modificar sua estrutura, textura e, com isso ampliar a capacidade de adsorção de substâncias tóxicas, pode ser uma alternativa importante e economicamente viável (Bojemueller et al., 2001; Elkhalifah et al., 2013). Neste contexto, a proposta deste estudo foi comparar a capacidade da bentonita in natura, extraída da região Sul do Estado de Santa Catarina, e da bentonita tratada termicamente, em adsorver a micotoxina $\mathrm{AFB}_{1}$.

\section{MATERIAL E MÉTODOS}

Amostras de bentonita: foram coletadas no município de Criciúma, Santa Catarina, região Sul do Brasil. Após coletadas, as amostras foram lavadas com água destilada para remoção de impurezas e, em seguida, secas. Depois de realizado o processo de lavagem o material (bentonita) foi tratado termicamente em forno mufla (Jung, N1100) a temperatura de $500{ }^{\circ} \mathrm{C}$, durante $4 \mathrm{~h}$.

Caracterização das amostras: (A) Espectroscopia no infravermelho com transformada de Fourier (FTIR): foram realizadas tanto para a bentonita in natura, quanto para bentonita tratada termicamente. Inicialmente, foram preparadas pastilhas de $\mathrm{KBr}$ contento $2 \%(\mathrm{p} / \mathrm{p}) \mathrm{de}$ amostra, sendo que os espectros no infravermelho foram obtidos em ampla região (de 450 a $4000 \mathrm{~cm}^{1}$ ), através do uso de espectrofotômetro (Shimadzu, IR Prestige-21) com transformada de Fourier. (B) Espectroscopia por dispersão de energia (EDS): a determinação dos principais elementos químicos presentes nas amostras foi realizada com sonda (Thermo, modelo 6733A-1NES-SN) acoplada a um microscópio eletrônico de varredura (Jeol, modelo JSM - 6390 LV).

Adsorção da $\mathrm{AFB}_{1}$ por UV-vis: os testes de adsorção in vitro das amostras de bentonita foram realizados em espectrofotômetro UV/vis (Q7980 Quimis) a $365 \mathrm{~nm}$. Para tal, foram adicionados $50 \mu \mathrm{L}$ de bentonita (concentração de $0,6 \mathrm{mg} / \mathrm{mL}$ ) a $1 \mathrm{~mL}$ de solução de $\mathrm{AFB}_{1}$ $(30 \mu \mathrm{M})$. As amostras foram deixadas overnight e centrifugadas (80-2B Centribio) a 2000 rpm, durante $57 \mathrm{~min}$.

\section{RESULTADOS E DISCUSSÃO}

Com o intuito de avaliar a perda de água e alterações nos percentuais de elementos químicos em amostras de bentonita in natura e tratada termicamente, análises de FTIR e EDS foram realizadas.

Com relação às características dos diferentes grupos de bentonita analisados, os resultados revelaram que bentonita tratada termicamente $\left(500{ }^{\circ} \mathrm{C}\right)$ apresentou perda de massa na ordem de 7,83\%, além de mudanças em sua coloração (Figura 1). 


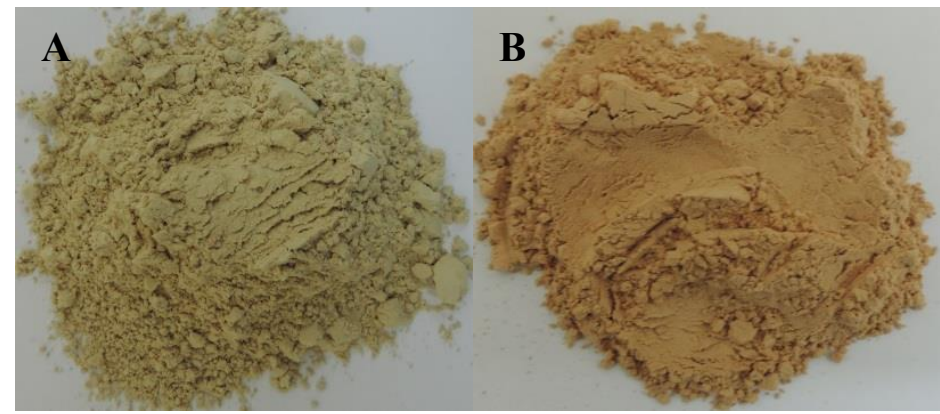

Figura 1 - Amostra de bentonita in natura (A) e calcinada (B).

A perda de água também foi avaliada através da análise de FTIR, confirmada pela redução das bandas em torno da região de $3500 \mathrm{~cm}^{-1}$ (Figura 2). Estes dados, associados à perda de massa, podem provavelmente ser atribuídos à desidratação e eliminação de cátions interlamelares (Rossetto et al., 2009). Da mesma forma, também foi possível observar no espectro a diminuição das bandas na região entre 450 e $1000 \mathrm{~cm}^{-1}$, as quais podem ser atribuídas à ligação entre silício, oxigênio e alumínio.

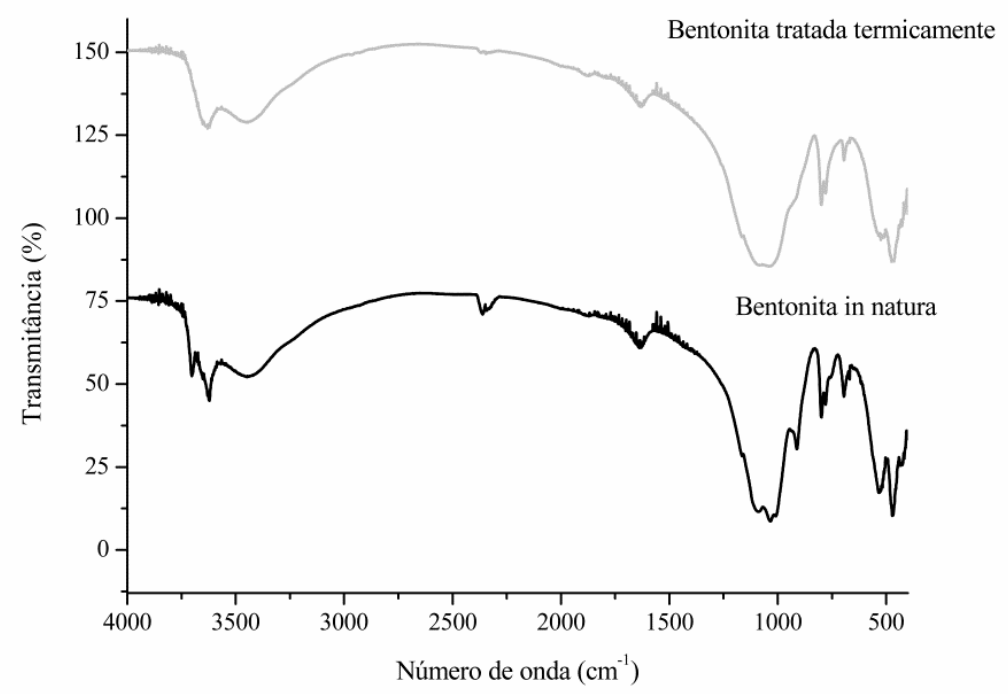

Figura 2 - FTIR da amostra de bentonita in natura e tratada termicamente.

Através da análise de EDS, pode ser observado que os elementos químicos mais abundantes presentes na amostra de bentonita in natura foram: O $(33,52 \%), \mathrm{C}(20,01 \%), \mathrm{Si}$ $(27,97 \%)$ e $\mathrm{Al}(9,65 \%)$. Outros elementos, como $\mathrm{Fe}, \mathrm{K}, \mathrm{Mg}$, $\mathrm{Ti}$ e $\mathrm{Na}$ foram encontrados em pequenas quantidades (abaixo de 6\%) (Tabela 1). Após calcinação, foram observadas reduções nos percentuais de $\mathrm{O}(30,71 \%), \mathrm{C}(15,87 \%), \mathrm{Fe}(2,96 \%), \mathrm{Mg}(0,19 \%)$ e $\mathrm{Ti}(0,0 \%)$ e aumentos nos percentuais de Si (34,33\%), Al (12,58\%), K (3,26\%) e $\mathrm{Na}(0,10 \%)$. Corroborando com os dados obtidos por Vieira et al. (2010), os resultados de EDS 
demonstram que praticamente não houve alterações significativas na composição química da bentonita após a realização do tratamento térmico.

Tabela 1 - Espectroscopia por dispersão de energia da bentonita in natura e tratada termicamente.

\begin{tabular}{ccc}
\hline \multirow{2}{*}{ Elemento } & \multicolumn{2}{c}{ Massa $(\%)$} \\
\cline { 2 - 3 } & In natura & Calcinada \\
\hline $\mathrm{O}$ & 33,52 & 30,71 \\
$\mathrm{C}$ & 20,01 & 15,87 \\
$\mathrm{Si}$ & 27,97 & 34,33 \\
$\mathrm{Al}$ & 9,65 & 12,58 \\
$\mathrm{Fe}$ & 5,09 & 2,96 \\
$\mathrm{~K}$ & 2,79 & 3,26 \\
$\mathrm{Mg}$ & 0,34 & 0,19 \\
$\mathrm{Ti}$ & 0,64 & 0 \\
$\mathrm{Na}$ & 0 & 0,10 \\
Total & 100,00 & 100,00 \\
\hline
\end{tabular}

Com o intuito de avaliar se a calcinação da bentonita poderia alterar a capacidade de adsorção quando comparado com a bentonita in natura, ensaios UV/vis de $\mathrm{AFB}_{1}$ foram realizados. Embora alguns estudos indiquem que o tratamento térmico pode aumentar a capacidade de adsorção (Masimango et al., 1978; Bojemueller et al., 2001), os resultados revelaram que este tratamento não foi capaz de aumentar a adsorção da $\mathrm{AFB}_{1}$, quando comparado com o grupo controle (bentonita in natura) (Figura 3).

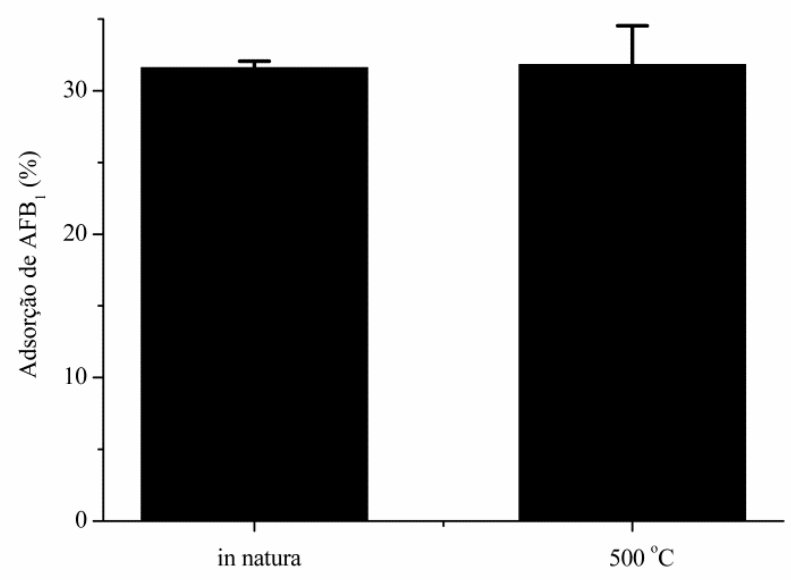

Figura 3 - Ensaio de adsorção da $\mathrm{AFB}_{1}$ das amostras de bentonita in natura e tratadas termicamente $\left(500{ }^{\circ} \mathrm{C}\right)$. Os resultados representam a média de dois experimentos independentes, realizados em duplicata. 


\section{CONCLUSÃO}

Os dados obtidos indicaram que o tratamento térmico da bentonita extraída de região Sul do Estado de Santa Catarina (realizado a $500{ }^{\circ} \mathrm{C}$ durante 4 horas) foi capaz de gerar pequenas modificações no que concerne a sua estrutura química, no entanto, não foi eficaz para o incremento da sua capacidade de adsorção. Considerando que outros fatores podem interferir nessa capacidade, alterações do tempo de calcinação (maior que 4 horas) ou aumento da temperatura de calcinação (Masimango et al., 1978; Bojemueller et al., 2001; Aytas et al., 2009), são hipóteses que precisarão ser testadas. Além disso, tratamentos ácidos, básicos, orgânicos e com íons metálicos (Dakovic et al., 2008; Komadel et al., 2006; Elkhalifah et al., 2013) também precisarão ser considerados como alternativas capazes de maximizar a capacidade de adsorção deste material e, consequentemente, otimizar o uso e a viabilidade econômica desta bentonita no combate de intoxicações causadas por micotoxinas.

\section{REFERÊNCIAS BIBLIOGRÁFICAS}

ALVER, B. E.; ALVER, O. The investigation of the effect of thermal treatment on bentonites from Turkey with Fourier transform infrared and solid state nuclear magnetic resonance spectroscopic methods. Spectrochim Acta A Mol Biomol Spectrosc, v. 94, p. 331-333, 2012.

AYTAS, S.; YURTLU, M.; DONAT, R. Adsorption characteristic of U(VI) ion onto thermally activated bentonite. J Hazar Mater, v. 172, p. 667-674, 2009.

BHUIYAN, I. U.; MOUZON, J.; SCHRÖPPEL, B.; KAECH, A.; DOBRYDEN, I.; FORSMO, S. P.E.; HEDLUND, J. Microstructure of bentonite in iron ore green pellets. Microsc. Microanal, v. 6, p. 1-9, 2013.

BOJEMUELLER, E.; NENNEMANN, A.; LAGALY, G. Enhanced pesticide adsorption by thermally modified bentonites. Appl Clay Sci, v. 18, p. 277-284, 2001.

CÓTICA, L.F.; FREITAS, V.F.; SANTOS, I.A.; BARABACH, M.; ANAISSI, F.J.; MIYAHARA, R.Y.; SARVEZUK, P.W.C. Cobalt-modified Brazilian bentonites: Preparation, characterisation, and thermal stability. Appl Clay Sci, v. 51, p. 187-191, 2011.

DAKOVIC, A.; MATIJASEVIC, S.; ROTTINGHAUS, G. E.; LEDOUX, D.R.; BUTKERAITIS, P.; SEKULIC, Z. Aflatoxin B1 adsorption by natural and copper modified montmorillonite. Colloids Surfaces B: Biointerfaces, v. 66, p. 20-25, 2008.

ELKHALIFAH, A.E.I.; MAITRA, S.; BUSTAM, M.A.; MURUGESAN, T. Effects of exchanged ammonium cations on structure characteristics and $\mathrm{CO}_{2}$ adsorption capacities of bentonite clay. Appl Clay Sci. v. 83-84, p. 391-398, 2013.

GIORDANO, B. N. E.; NONES, J.; SCUSSEL, V.M. Susceptibility of the in shell Brazil nut mycoflora and aflatoxin cantamination to ozone gas treatment during storage. J Agricultural Science, v. 4, p. 1-10, 2012. 
HAMIDI, A.; MIRNEJAD, R.; YAHAGHI, E.; BEHNOD, V.; MIRHOSSEINI, A.; AMANI, S.; SATTARI, S.; DARIAN, E. K. The aflatoxin B1 isolating potential of two lactic acid bacteria. Asian Pac J Trop Biomed, v. 3, p. 732-736, 2013.

KOMADEL, P.; MADEJOVÁ, J. Acid activation of clay minerals, in: F. Bergaya, B.K.G. Theng, G. Lagaly (Eds.), Handbook of Clay Science, Amsterdam, Elsevier 2006.

MAGNOLI, A. P.; TALLONE, L.; ROSA, C.A.R.; DALCERO, A.M.; CHIACCHIERA, S. M.; SANCHEZ, R. M. T. Commercial bentonites as detoxifier of broiler feed contaminated with aflatoxin. Appl. Clay Sci., v. 40, p. 63-71, 2008.

MALLMANN, C.A.; DIKIN, P. Mycotoxins and Mycotoxicoses in Swine. Special nutrients: the Mycotoxins specialist, Copyright, 2011.

MASIMANGO, N.; REMACLE, J.; RAMZUT, J.L. the role of adsorption in the elimination of aflatoxin b1 from contaminated media european $J$ Appl Microbiol Biotechnol, v. 6, p. 101$105,1978$.

NONES, J.; HORN, M. B.; LUCHTENBERG, R.; NONES, J.; SCUSSEL, V.M. Nutritional quality and safety assessment of ingredients and feed. Pubvet, v. 6, p. 1-18, 2012.

NONES, J.; NONES, J.; TRENTIN, A. Flavonoid hesperidin protects neural crest cells from death caused by aflatoxin $\mathrm{B}_{1}$. Cell Biol Int, v. 37, p. 181-186, 2013.

ROSSETTO, E.; BERALDIN, R.; PENHA, F. G.; PERGHER, S. B. C. Caracterização de argilas bentonitas e diatomitas e sua aplicação como adsorventes. Quim. Nova, v. 32, p. 20642067, 2009.

SHIM, W.B.; MUN, H.; JOUNG, H.A.; OFORI, J.A.; CHUNG, D.H.; KIM, M.G. Chemiluminescence competitive aptamer assay for the detection of aflatoxin B1 in corn samples. Food Control, v. 36, p. 1-30, 2014.

VIEIRA, M.G.A.; ALMEIDA NETO, A.F.; GIMENES, M.L.; SILVA, M.G.C. Removal of nickel on Bofe bentonite calcined clay in porous bed. J Hazar Mater, v. 176, p. 109-118, 2010 . 